\title{
Eksistensi Pasraman Dalam Menanamkan Nilai Moral Bagi Umat Hindu
}

\author{
I Putu Suarnaya \\ STKIP Agama Hindu Singaraja \\ suarnayaiputu@gmail.com
}

DOI : $10.37329 /$ cetta.v3i2.450

\begin{tabular}{l}
\hline Keywords: \\
\hline Pasraman; Moral \\
Education \\
\hline
\end{tabular}

\begin{abstract}
Bali Island as a foreign tourist destination, aware or not possible to be affected by the interaction with tourists who come to Bali and cause acculturation of foreign culture with local culture. Acculturation of positive culture enriches local culture while the influence of negative foreign culture can damage, mencedrai and even shift the existence of local culture, for that the necessary antidote to negative foreign culture through education in pasraman. The aim of this study. describe the existence of pasraman Brahma Vidya Samgraha Penarungan Village, Buleleng Regency; Describe the implementation of education in Pasraman Brahma Vidya Samgraha; Penarungan Village, Buleleng Regency; Describing the planting of moral education in the Brahma Vidya Samgraha Penarungan Village, Buleleng Regency. This research uses descriptive-qualitative method with a phenomenological approach. The findings in this study of the existence of Pasraman Brahma Vidya Samgraha are an acculturation of the education system that is the traditional education system and the modern or contemporary education system. The implementation of ceremonies (rituals) through the routine of making ceremonial facilities carried out in pasraman. Conclusion: Pasraman Brahma Vidya Samgraha is a type of non-formal education acculturated with the education system of Color Dormitory Dharma with the transformation of the upanisad learning model based on vedic culture; Pasraman Brahma Vidya Samgraha conducts adult learning (andragogy) with teaching programs in accordance with the level of basic education, middle level education and primary level of education, by applying a varied upanisad learning model; Pasraman Brahma Vidya Samgraha implements moral values in Pasraman as a spiritual commitment through the mutual assistance activities of the sisya in the process of making ceremonies and conducting ceremonies in Pasraman.
\end{abstract}

\begin{tabular}{l}
\hline Kata Kunci: \\
\hline Pasraman; \\
Pendidikan \\
Moral \\
\hline
\end{tabular}

Abstrak
Pulau Bali sebagai destinasi wisata manca negara, sadar atau
tidak dimungkinkan terkena dampak dari interaksi dengan
para wisatawan yang datang ke Bali dan menyebabkan


terjadinya akulturasi budaya asing dengan budaya local. Akulturasi budaya positif memperkaya budaya local sedangkan pengaruh budaya asing negative dapat merusak, mencedrai bahkan menggeser eksistensi budaya lokal, untuk itu diperlukan spirit penangkal budaya asing negatif melalui pendidikan di pasraman. Penelitian ini bertujuan mendiskripsikan eksistensi pasraman Brahma Vidya Samgraha Desa Penarungan Kabupaten Buleleng; Mendiskripsikan pelaksanaan pendidikan di pasraman Brahma Vidya Samgraha; Desa Penarungan Kabupaten Buleleng; Mendiskripsikan penanaman nilai pendidikan moral di pasraman Brahma Vidya Samgraha Desa Penarungan Kabupaten Buleleng. Penelitian ini menggunakan metode Deskriptif-kualitatif dengan pendekatan fenomenologis. Hasil temuan dalam penelitian ini terhadap eksistensi pasraman Brahma Vidya Samgraha merupakan akulturasi sistem pendidikan yaitu sistem pendidikan tradisional dan sistem pendidikan modern atau kekinian, Hasil temuan model pembelajaran di pasraman ini menggunakan metode campuran (Mixe Method), Hasil temuan penanaman nilai pendidikan moral dalam proses pembuatan pelaksanaan upacara (ritual) melalui rutinitas pembuatan sarana upacara yang dilaksanakan di pasraman. Simpulan: Pasraman Brahma Vidya Samgraha merupakan jenis pendidikan non formal berakulturasi dengan sistem pendidikan Warna Asrama Dharma dengan transformasi model pembelajaran upanisad berdasarkan budaya weda; Pasraman Brahma Vidya Samgraha melaksanakan pembelajaran orang dewasa (andragogy) dengan program ajar sesuai dengan tingkat pendidikan dasar, tingkat pendidikan madya dan tingkat pendidikan utama, dengan menerapkan model pembelajaran upanisad bervariasi; Pasraman Brahma Vidya Samgraha menanaman nilai moral di pasraman sebagai komitmen spiritual melalui kegiatan gotong royong para sisya dalam proses pembuatan upakara dan pelaksanaan upacara di pasraman.

\section{Pendahuluan}

Berbicara mengenai pasraman sampai saat ini masih tetap diminati untuk dikaji, diteliti, dan dikembangkan karena bersifat unik. Beberapa penelitian tentang pasraman dilakukan oleh Atyani menemukan ada pengaruh positif dan signifikan peran pasraman terhadap penguatan karakter membaca...(2019). Peneliti lain mengungkapkan pengelolaan pasraman dapat menguatkan budaya lokal... (Subagia, 2017) dan Hasil penelitian Sila tentang pasraman menunjukkan dimana pasraman 
memiliki fungsi strategis dalam menumbuhkan sikap revolusi mental melalui revitalisasi manajemen di pasraman...(20016). Dalam penelitian ini secara kajian sama tentang pasraman namun aspek dan hasil temuannya yang berbeda. Penelitian ini secara garis besar ada perbedaan dari penelitian sebelumnya, baik dari subyek, obyek, lokasi, permasalahan yang di kaji dan hasil penelitiannya sehingga memberikan peluang untuk diteliti kembali.

Keunikan keberadaan pendidikan di pasraman mampu mengelaborasi pendidikan abad ke-21 yang diwarnai dengan pengaruh-pengaruh globalisasi sehingga memiliki wawasan global. Namun pembelajaran di pasraman mengelaborasi kearah demokratisasi belajar dan merdeka belajar, “bertumpu pada empat pilar belajar yaitu learn to know, learn to to, learn to be dan learn to life to gether sehingga memiliki ketrampilan hidup (life skill)" (Naradha, 2004:155). Sejalan dengan itu maka peradaban dalam masyarakat akan sangat dipengaruhi oleh sistem pendidikan yang diberikan dalam masyarakat tersebut. Masyarakat yang memperoleh pendidikan yang tepat akan menghasilkan masyarakat yang beradab dan dengan masyarakat yang bermoral dan berperikemanusiaan. Tetapi sistem pendidikan yang salah akan menghasilkan masyarakat yang meskipun menguasai IPTEK tetapi tidak memiliki moral. Pandangan tersebut menunjukkan bahwa pendidikan adalah cara untuk membentuk peradaban manusia. Dengan pendidikan yang bagus dan benar maka arah peradaban dapat ditujukan kepada arah yang benar dan bermanfaat. Bermanfaat disini tentu berarti lebih komprehensif daripada manfaat-manfaat duniawi yang sering kita unggulkan sementara ini. Umat Hindu masa kini tentu saja mau tidak mau juga menjadi bagian dalam perkembangan dunia kekinian (global). Umat Hindu terlibat langsung dalam semua aspek dalam kehidupan ini sebagai pribadi yang beragama Hindu maupun sebagai mahluk religius yang memiliki keyakinan kehinduan sebagai jalan dan pilihan hidupnya.

Kegagalan paradigma modern dalam membangun manusia dan peradaban manusia merupakan kelemahan dalam dunia pendidikan maka diperlukan kajian pendidikan menurut pandangan Agama, sebagai perbandingan yang berguna sebagai acuan agar paradigma modern dapat diteliti letak kelemahan konsep-konsepnya, sejalan dengan tumbuh dan berkembangnya kesadaran masyarakat akan pendidikan (Naradha, 2004:152). Berdasarkan kajian emperik maka konsep pendidikan yang diharapkan saat ini adalah konsep akulturasi pendidikan tradisional dengan 
pendidikan kekinian. Pendidikan tradisional telah menjadi fitur sistem pendidikan selama berabad-abad (Martin et al., 2014). Konsep akulturasi pendidikan ini akan melahirkan pendidikan berdasarkan lokal genius namun berwawasan global (Think Localy and Act Globaly) dalam wujud pendidikan di pasraman. Dalam hal ini pendidikan di pasraman menanamkan adanya nilai-nilai pendidikan yang ditransformasikan berdasarkan moral agama Hindu yang bersumber dari kitab suci weda dan sastra agama Hindu.

\section{Metode}

Penelitiaan ini termasuk penelitian Kualitatif, dengan pendekatan fenomenologis, berlangsung dari bulan Mei-Juli 2019 yang berlokasi di Pasraman Brahma Vidya Samgraha Desa Penarungan Kecamatan Buleleng Kabupaten Buleleng. Target/sasaran penelitian ini adalah narasumber atau informan yang diperoleh secara purposive dan snowball yang meliputi: Pandita Nabe, Pimpinan pengelola pasraman dan para pengajar (pendamping) dan sisya/murid. Subyek penelitian dalam penelitian ini adalah penanaman pendidikan nilai moral. Prosedur penelitian yang peneliti lakukan adalah: Memilih topik kajian; Instrumentasi; Pelaksanaan Penelitian; Pengolahan data dan Hasil penelitian (Satori \& Aan Komariah, 2010:82). Proses penelitian didahuli dengan studi lapangan, melaksanakan penelitian di pasraman Brahma Vidya Samgraha, sampai menarik kesimpulan sementara dari temuan penelitian, dan menarik simpulan penelitian.

\section{Hasil Dan Pembahasan}

\section{Eksistensi Pasraman Brahma Vidya Samgraha Desa Penarungan Kecamatan} Buleleng Kabupaten Buleleng.

Eksistensi sistem pendidikan di pasraman Brahma Vidya Samgraha sangat berorientasi pada ajaran-ajaran Agama Hindu. Karena perkembangan jaman dalam bidang pendidikan, teknologi informasi maka pasraman yang ada sekarang merupakan sistem pendidikan tradisional yang melebur dengan sistem pendidikan modern namun masih tetap berakar pada budaya setempat atau kearifan lokal. Pasraman atau disebut juga ashram merujuk pada pengertian tempat untuk melaksanakan kegiatan atau interaksi sosial edukatif. (Yuli, Haningsih and Adikrishna, 2011) Hal ini sejalan dengan hasil penelitian Agung dan Musta (1992). Pendidikan di 
pasraman lebih menekankan pada pendidikan Agama Hindu yang bersifat rohaniah seperti disiplin diri, mengembangkan akhlak mulia dan sifat-sifat yang rajin, suka bekerja keras, pengekangan hawa nafsu dan gemar untuk menolong orang lain, serta pendalaman tattwa, susila dan pelaksanaan upacara agama Hindu sesuai dengan tingkat kematangan diri seseorang secara fisik dan mental. Selanjutnya dinyatakan konsep pasraman yang berkembang sekarang diadopsi dari sistem pendidikan Hindu zaman dahulu di India, sebagaimana disuratkan dalam kitab suci Weda dan hingga kini masih tetap terpelihara. Sistem ashram menggambarkan hubungan yang akrab antara para guru (acarya) dengan para sisyanya, bagaikan dalam sebuah keluarga. Oleh karena itu, sistem ini dikenal pula dengan dengan para nama sistem pendidikan gurukula (Widnya,2017:161 \& Subagia, 2017). Sistem ini menjelaskan metode transmisi pengetahuan dari guru ke murid pada saat pencerahan spiritual dalam tradisi India kuno (Rao, 2010).

Beberapa anak didik tinggal di pasraman bersama para guru sebagai anggota keluarga dan para guru bertindak sebagai orang tua siswa sendiri. Selaras dengan hal tersebut maka proses pendidikan di pasraman dari masa lampau itu masih tetap berlangsung sampai saat ini dikenal pula dengan istilah lainnya yakni parampara, padepokan, guru kula, aguron-guron dan bentuk lainnya dalam bentuk satuan pendidikan atau program (Widnya,2017:168 \& Subagia, 2017). Dalam tradisi Hindu ada asram dan guru kula. Dalam interaksi pendidikan di pasraman ada komponen yang terlibat di dalamnya seperti guru dengan berbagai sebutannya seperti Mpu, Nabe, Dang guru sebagai orang yang lebih dewasa untuk membimbing para sisya atau murid. Interaksi pendidikan tersebut dikelola melalui Warna Asrama Dharma (Widnya,2017:163). Berdasarkan pada uraian di atas maka pendidikan tradisional Hindu dengan sistem asrama merupakan pendidikan non formal yang dilakukan oleh pemerintah atau raja, dan atau masyarakat serta di rumah tangga dengan istilah asrama, wihara, paguron kraton, dan keluarga sebagai tempat interaksi sosial ini menyebabkan terjadinya transformasi nilai adat, agama, terdisi dan budaya secara berkelanjutan dari generasi ke generasi. Pendidikan dalam hal ini menganut sistem pembiasaan serta contoh perilaku dari para tetua atau pun guru dengan segala keterbatasannya.

Landasan pendidikan pasraman Brahma Vidya Samgraha sangat berorientasi pada ajaran-ajaran Agama Hindu salah satunya adalah Catur Asrama, dalam ajaran agama Hindu membagi tingkat penghidupan manusia menjadi empat masa yang 
dikenal dengan istilah Catur Asrama (Widnya,2017:163). Brahmacharya Asrama: tingkat hidup berguru; Grihastha Asrama: tingkat hidup berumah tangga; Wanaprastha Asrama: tingkat hidup mengasingkan diri/menenangkan diri yang jauh dari kebisingan; Samnyasa Asrama: tingkat hidup sebagai seorang sanyasin. Dalam masa tingkat hidup berguru atau aguron-guron yang disebut Brahmacharya, mempunyai pengertian yang berdasar pada pandangan masyarakat Hindu terhadap hidup atau kelahiran dua kali, yaitu lahir yang pertama kali adalah lahir dan ibu, sedangkan lahir yang kedua kali adalah lahir ke dunia ilmu sehingga bagi merka yang telah menjalani kehidupan yang kedua mereka disebut dwijati.

Dalam etika aguron-guron memasuki masa berguru ini didahului dengan upacara penyucian yang disebut Upanayana, dan apabila masa Brahmacharya ini sudah berakhir maka diakhiri dengan suatu upacara pelepasan yang disebut Samavartana (wisuda sekarang). Hal ini diarahkan untuk menjadikan para siswa/sisya calon pinandita dan sarati banten memiliki mental yang kuat, memiliki moral yang baik, serta memiliki rasa pengabdian yang tulus dan mampu bertanggung jawab kepada umat, dirinya sendiri serta bangsa dan negara. Hal tersebut sesuai dengan Visi dan Misi dari Pasraman Brahma Vidya Samgraha yaitu:

“Terwujudnya Sumber Daya Manusia (SDM) yang berkwalitas khususnya para Pinandita, berkepribadian luhur, bersahaja yang dilandasi dengan rasa bhakti kepada Ida Sang Hyang Widhi Wasa dan Leluhur serta mengabdi kepada umat. Salah satu misinya adalah: Membangun intelektualitas dan moralitas umat berdasarkan falsafah Tri Hita Karana" (sumber: dokumen Profil Brahma Vidya Samgraha :2010)

Hasil temuan dalam penelitian ini terhadap eksistensi pasraman Brahma Vidya Samgraha merupakan akulturasi sistem pendidikan yaitu sistem pendidikan tradisional dan sistem pendidikan modern atau kekinian. Pendidikan tradisional Hindu di pasraman masih diterapkan dengan pembelajaran dimana siswa/sisya duduk dekat dengan tekun atau juga dikenal dengan istilah Upanisad (Prabhavananda,2006:41). Sistem pendidikan modern diadopsi karena para sisya/siswa tidak tinggal bersama guru, artinya para sisya setelah pembelajaran pulang ke rumah masing-masing hal ini dimungkinkan karena perkembangan jaman yang dapat mempengaruhi sistem pendidikan di pasraman atau pendidikan berdasarkan lokal genius namun berwawasan global (Think Localy and Act Globaly). Pasraman dalam 
Sistem Pendidikan Nasional saat ini merupakan bagian dari jalur pendidikan non formal (Sisdiknas, Bab VI;pasal 14 \& 55; Sila (2016) \& Subagia, 2017). Berdasarkan paparan di atas maka dapat disimpulkan pasraman Brahma Vidya Samgraha merupakan jenis pendidikan non formal berakulturasi dengan sistem pendidikan Warna Asrama Dharma dengan transformasi model pembelajaran upanisad berdasarkan budaya weda.

\section{Pelaksanaan Pendidikan di Pasraman Brahma Vidya Samgraha Desa Penarungan Kecamatan Buleleng Kabupaten Buleleng.}

Pendidikan di Pasraman Brahma Vidya Samgraha berlangsung dengan pembelajaran andragogy (pendidikan orang dewasa), karena para siswa/sisya rata-rata berusia 25 tahun ke atas dengan latar belakang tingkat pendidikan, sosio-kultural yang berbeda. Fokus pendidikan di pasraman ini adalah menghasilkan calon pinandita dan sarati banten yang memiliki kualifikasi berdasarkan ketentuan yang berlaku dari lembaga Parisadha Hindu Dharma Indonesia (PHDI) dan sastra agama Hindu. Pembelajaran di laksanakan secara bertatap muka langsung dengan duduk melingkar dan di damping atau dibimbing oleh seorang guru (Upanisad). Dalam pembelajaran dipasraman ini para sisya di bagi menjadi beberapa kelompok tingkat yaitu:

Kelompok tingkat pratama merupakan pembelajaran tahap awal, baik orang itu kejumput, ngiring di salah satu pura atau dia datang karena inggin mempelajari tattwa kepinanditaan yang nantinya berguna untuk dirinya sendiri. Dilihat dari kata Pemangku yang artinya orang yang bertanggung jawab atas apa yang dimilikinya, tidak hanya memangku pada tempat orang itu ngiring tapi di rumah masing-masing ada tanggung jawab yang lebih besar. Materi yang diberikan pada tingkatan ini ditekankan adalah masalah etika, pembuatan piranti dalam pemujaan, memahami sarana prasarana yang di gunakan, dan tetikasan tingkat dasar. Sisya yang telah melalui proses pembelajaran selama kurang lebih 3 (tiga) bulan dan setelah melalui proses evaluasi dan dinyatakan memenuhi syarat maka dilaksanakan upacara upanayana atau pewintenan alit maka diberikan Tanggung jawab serta kewenangan hanya pada kegiatan pengastawa tirta/air suci yang alit/kecil, ngulapin, purnama dan tilem, serta mecaru eka sato. Para sisya yang telah melalui proses dan memenuhi persyaratan yang telah ditetapkan oleh pengelola pasraman maka diberikan gelar pada tingkat pratama adalah Pemangku. 


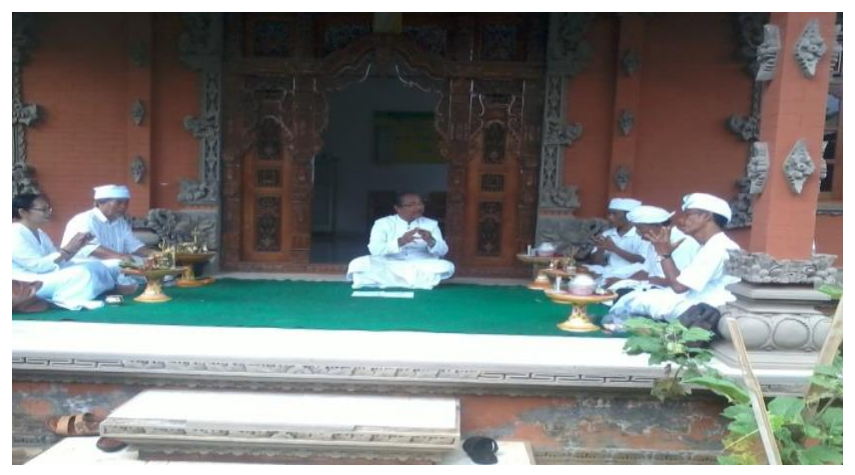

Gambar 1 Pembelajaran tingkat pratama (Suarnaya:2019)

Kelompok tingkat madya merupakan lanjutan pembelajaran dari tingkat pratama awal para sisya sudah mempelajari ngastawa tirta ageng/jangkep yang merupakan ageman sang sulinggih, bisa membuat tirta penglukatan, tetikasan semakin dimantapkan serta sudah bisa menyelesaikan kegiatan upacara yang lebih besar seperti upacara tiga bulanan. Pada tingkatan ini pelajaran yang diberikan agak rumit dan kompleks, selain gerakan-gerakan yang lebih banyak juga mantra-mantra yang harus diingat lebih banyak sesuai dengan tugas dan tanggung jawab yang dimiliki dalam menyelesaikan upacara. Para sisya yang telah melalui proses kurang lebih 3 (tiga) bulan dan dinyatakan memiliki kompetensi untuk tingkat madya maka melalui upacara upanayana (pewintenan) diberikan gelar Jro Mangku.

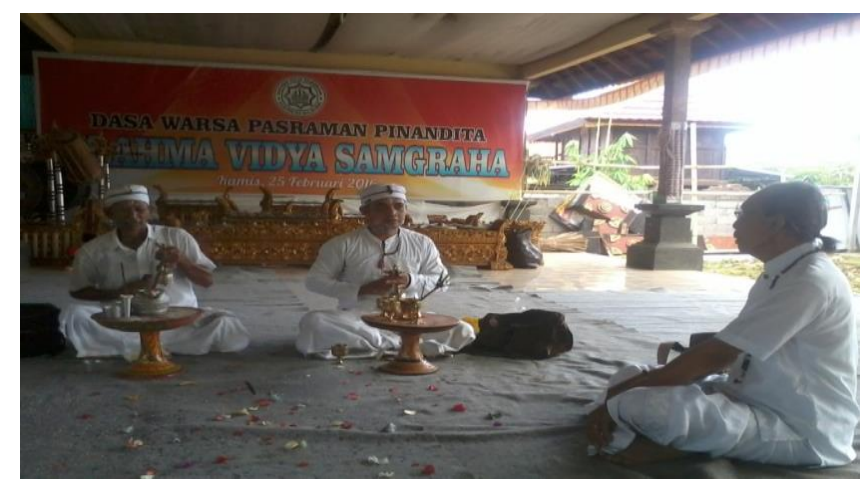

Gambar 2 Pembelajaran tingkat madya (Suarnaya:2019)

Kelompok tingkat utama merupakan tingkat lanjutan dari tingkat madya dimana para sisya bersifat pemantapan lebih lanjut materi ajar yang sudah di ajarkan pada tingkat madya. Sisya yang sudah melalui proses selama kurang lebih 3(tiga) bulan dan dinyatakan memenuhi peryaratan kulifikasi maka sisya tersebut diberikan gelar Jro Gede. Tugas dan tanggung jawab seorang Jro Gede diberikan kewenangan oleh guru nabe bisa melakukan Loka Phala Sraya serta menyelesaikan upacara pada upacara Panca Yadnya kecuali Rsi Yadnya. Bilamana sang sisya terus mendalami pebelajaran tingkat 
utama ini dan telah melalui proses sesuai ketentuan di pasraman dan dinyatakan memiliki kompetensi untuk itu maka sisya tersebut di berikan gelar Bhawati. Kelanjutan aguron-guron setelah bergelar Bhawati adalah menjadi Sulinggih dan ini tidak semua sisya mau meningkatkan diri menjadi sulinggih karena dirasakan berat dari persyaratan, dan harus siap fisik dan mental.

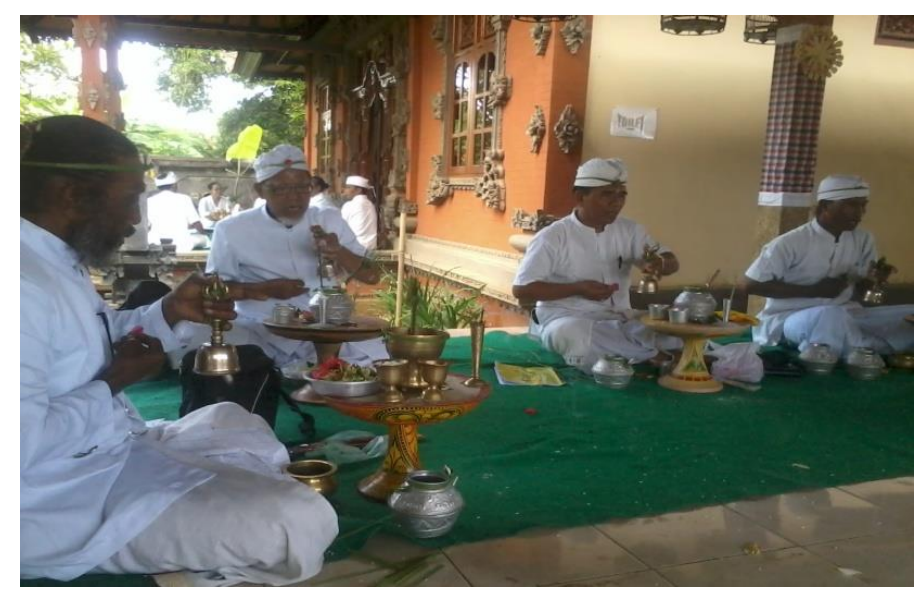

Gambar 3 Pembelajaran tingkat utama (Suarnaya: 2019)

Berdasarkan data emperis dimana pembelajaran di pasraman Brahma Vidya Samgraha menerapkan metode campuran dimana sistem pembelajaran upanisad dipadukan dengan sistem pembelajaran modern yang menekankan pada proses pengamatan (observasi), pemodelan (modeling) dari pendamping, melakukan kegiatan dengan mencoba mempraktekan apa yang sudah dipelajari (demonstrasi), merapalkan doa atau mantra berulang ulang (drill), diskusi dan Tanya jawab. Pembelajaran dengan metode campuran dimungkinkan dalam kelompok adanya interaksi antar individu dalam proses pembelajaran. Hal ini sejalan dengan pendapat Wenger (1998) dimana Interaksi satu orang dengan orang lain dalam kelompok dapat membantu individu menjalani proses pembelajaran yang lebih positif dibandingkan ketika hanya mengerjakan atau belajar mandiri (Wenger, 1998 dalam Huda,2014:49). Selanjutnya dinyatakan pembelajaran seperti ini terjadinya perkembangan dalam individu dalam hal pemikiran, gagasan dan pemahaman terhadap diri individu yang bersangkutan dan juga tentu juga tidak lepas dari pengaruh orang lain atau masyarakat sekitarnya.

Hasil temuan model pembelajaran di pasraman ini menggunakan metode campuran (Mixe Method). Metode ini merupakan elemen didaktis yang disesuaikan digabungkan dan diintegrasikan dengan tujuan untuk meningkatkan kualitas 
pendidikan (Köttgen et al., 2016), yang selama ini diterapkan dapat membantu para sisya dalam memahami materi ajar yang sudah diajarkan sudah mampu mengiplementasikan dalam kegiatan upacara keagamaan Hindu atau kegiatan lain yang menjadi tanggung jawab para sisya.

Pasraman Brahma Vidya Samgraha secara kelembagaan dapat disebut sebagai pendidikan non formal yang diselenggarakan oleh masyarakat berkhaskan keagamaan (Sisdiknas Bab VI; pasal 55: ayat 1), dengan konten program yang sudah disiapkan secara bertingkat mulai dari tingkat dasar, tingkat madya dan tingkat utama dengan upanisad bervariasi dari pendamping ke para sisya. Dari hasil penelitian di lapangan secara implisit kurikulum sudah diterapkan dari satu angkatan ke angkatan berikutnya menyesuaikan dengan kekhasan pendidikan non formal namun tetap mengacu pada kurikulum sisdiknas Bab X; pasal 36: ayat 3). Berdasarkan paparan di atas terkait dengan pelaksanaan pendidikan di pasraman Brahma Vidya Samgraha dapat disimpulkan pasraman Brahma Vidya Samgraha melaksanakan pembelajaran orang dewasa (andragogy) dengan program ajar sesuai dengan tingkat pendidikan dasar, tingkat pendidikan madya dan tingkat pendidikan utama, dengan menerapkan model pembelajaran upanisad dengan metode campuran atau bervariasi.

\section{Penanaman Nilai Pendidikan Moral di Pasraman Brahma Vidya Samgraha Desa Penarungan Kecamatan Buleleng Kabupaten Buleleng.}

Secara umum pendidikan yang dilaksanakan oleh pemerintah pemerintah daerah dan/atau masyarakat mengacu pada Sistem Pendidikan Nasional Bab X; pasal 36: ayat 3 dengan menekankan beberapa hal-hal terkait dengan peningkatan iman dan takwa, peningkatan ahlak mulia (karakter, moral), agama, termasuk interaksi dan hubungan positif dengan teman sebaya (Lester and Mander, 2015 ; Atyani;2019)). Penanaman nilai pendidikan moral yang ditransformasikan melalui proses pembelajaran mengacu pada moral agama Hindu yang mengacu pada Tri Kerangka Agama Hindu yang meliputi: Tattwa (filsafat), Susila (Etika) dan Upacara (ritual). Berdasarkan data emperis penanaman nilai tattwa di pasraman mengacu pada keimanan atau keyakinan terhadap Panca Sraddha yaitu keyakinan terhadap Tuhan Yang Maha Esa (Brahman), keyakinan dengan adanya Atman (roh leluhur), keyakinan dengan adanya hukum karma phala (hukum sebab akibat), keyakinan dengan adanya punarbhawa (samsara) dan keyakinan dengan adanya moksa (Maswinara, 2002). 
Hasil temuan penanaman nilai pendidikan Pasraman menawarkan perspektif yang berpotensi unik pada iklim pendidikan karena inetraksi pendidikan terjadi dalam iklim sosial diberbagai tingkat struktur pendidikan (Martin et al., 2015). Penanaman nilai dalam Panca sraddha merupakan satu kesatuan dalam kehidupan para sisya sehari hari. Penanaman nilai moral yang ada dalam tattwa selalu mengucapkan rasa syukur atas anugrah dari Ida Sang Hyang Widhi Wasa (Tuhan) dan menyadari keberadaan Tuhan melalui penerapan japa mantra,yang merupakan metode klasik transmisi pengalaman spiritual dengan mendengarkan, berpikir reflektif dan bermeditasi (Sravana, Manana dan Nidhidhyasana) (Rao, 2010), selain itu menjaga hubungan yang harmonis dengan sesama yang bersumber dari Tuhan, menghargai sesama dan penerapan ajaran Tat twam Asi yang mengajarkan persamaan rasa sosial, senasib sepenanggungan, toleransi, kasih sayang (dalam arti luas) dengan sesama.

Berdasarkan paparan diatas dapat disimpulkan mengenai penanaman nilai moral agama Hindu pada tatanan sraddha di pasraman Brahma Vidya Samgraha dengan mengucapkan rasa syukur kepada Tuhan; merapalkan japa mantra; menjaga hubungan harmonis dengan Tuhan, sesama dan lingkungan sekitar; memiliki rasa toleransi; dan memiliki rasa kasih sayang dalam arti luas.

Penanaman nilai pendidikan moral (etika) dalam aktivitas pembelajaran di Pasraman Brahma Vidya Samgraha melalui ajaran pengendalian diri berupa pelaksnaan Tri Kaya Parisudha (Kajeng,2009 \& Suhardana,2007) yaitu: Manacika Parisudha : mengembangkan pikiran yang baik dan benar. Berpikir yang baik dan benar adalah berpikir yang bersih, positif, jernih, obyektif, dan bermanfaat. Wacika Parisudha: berkata atau berbicara yang baik dan benar, berkata yang sopan, berkata mengandung makna yang baik dan mulia, berkata tidak menimbulkan kesalah pemahaman dan kemarahan orang lain. Kayika Parisudha: berbuat yang baik dan benar dalam melakukan aktivitas untuk keperluan memenuhi kewajiban hidup, memberi manfaat bagi orang lain, mencapai kesejahteraan, dan keselamatan kehidupan diri sendiri dan orang lain.

Secara umum kegiatan upacara yadnya meliputi kegiatan upacara Panca Yadnya (Pemda Tk.I Bali, 2000). Hasil temuan dilapangan menunjukkan penanaman nilai pendidikan moral dalam Upacara (ritual) Proses pembelajaran di Pasraman Brahma Vidya Samgraha melalui rutinitas pembuatan sarana upacara yang dilaksanakan di pasraman. Para sisya belajar ke pasraman dimana sisya perempuan belajar mendalami 
tentang tatacara pembuatan banten, sisya laki-laki lebih fokus belajar kepinanditaan walau kedua kompetensi tersebut dipelajari secara bersama-sama. Pembuatan sarana persembahyangan dan upacara yang digunakan di Pasraman Brahma Vidya Samgraha sebagai wujud rasa bhakti para sisya kepada Ida Sang Hyang Widhi Wasa (Tuhan). Pembuatan sarana upacara ini juga dapat menjalin rasa kekeluargaan yang tinggi dari semua anggota pasraman. Upakara yang telah dibuat dan dipersembahkan tersebut mencerminkan nilai rasa bhakti kepada Ida Sang Hyang Widhi Wasa (Tuhan). Nilai kebersamaan dimana para sisya belajar bersama-sama dan juga sebagai pencerminan rasa hormat kepada guru (Sagala, 2015), pencerminan nilai sikap kekeluargaan antara keluarga pengelola pasraman dengan para sisya dapat disebut sebagai komitmen spiritual (Trammell, 1999).

Berdasarkan paparan di atas maka dapat disimpulkan penanaman nilai moral dipasraman melalui implementasi nilai filsafat, nilai etika dan nilai ritual sebagai komitmen spiritual tercermin dari kegiatan gotong royong para sisya dalam pembuatan upakara dan pelaksanaan upacara di pasraman.

\section{Simpulan}

Pasraman Brahma Vidya Samgraha merupakan jenis pendidikan non formal berakulturasi dengan sistem pendidikan Warna Asrama Dharma dengan transformasi model pembelajaran upanisad berdasarkan budaya weda dan sastra agama Hindu. Pasraman Brahma Vidya Samgraha melaksanakan pembelajaran orang dewasa (andragogy) dengan program ajar sesuai dengan tingkat pendidikan dasar, tingkat pendidikan madya dan tingkat pendidikan utama, dengan menerapkan model pembelajaran upanisad bervariasi. Pasraman Brahma Vidya Samgraha menanaman nilai moral di pasraman sebagai komitmen spiritual melalui kegiatan gotong royong para sisya dalam pembuatan upakara dan pelaksanaan upacara di pasraman.

\section{Daftar Pustaka}

Agung, AA G. P. \& Musta, I N. (1992). Sejarah Pendidikan Daerah Bali. Depdikbud Dirjen Kebudayaan. Jakarta: Depdikbud.

Atyani, N. (2019). Peran Pasraman Sebagai Wahana Penguatan Karakter Gemar Membaca Pada Anak Di Desa Mulya Sari Kecamatan Negeri Agung Kabupaten Way Kanan.

Kadjeng, I N. (2009). Sarasamuccaya. Surbaya: Paramita 
Köttgen, L. et al. (2016) 'Integrating Blended Learning - On the Way to an Excellent Didactical Method-Mix for Engineering Education', in Automation, Communication and Cybernetics in Science and Engineering 2015/2016, pp. 339-352. doi: 10.1007/978-3-319-42620-4_27.

Lester, L. and Mander, D. (2015) ‘The Role of Social, Emotional and Mental Wellbeing on Bullying Victimisation and Perpetration of Secondary School Boarders', Journal of Psychologists and Counsellors in Schools, 25(2), pp. 152-169. doi: 10.1017/jgc.2014.28.

Martin, A. J. et al. (2014) ‘Boarding School, Academic Motivation and Engagement, and Psychological Well-Being', American Educational Research Journal, 51(5), pp. 10071049. doi: $10.3102 / 0002831214532164$.

Martin, A. J. et al. (2015) 'Motivation, engagement, and social climate: An international study of boarding schools', Journal of Educational Psychology, 108(6), pp. 772-787. doi: $10.1037 /$ edu0000086.

Miles \& Huberman.(2014). Analisis Data Kualitatif.Jakarta: Universitas Indonesia.

Naradha, S. (2004). Ajeg Bali Sebuah Cita-Cita. Denpasar: Bali Post.

Prabavananda,Swami. (2006). Agama Weda E Filsafat. Surabaya: Paramita.

Rao, D. N. N. (2010) ‘Knowledge Transfer for Spiritual Enlightenment: Master-Disciple Tradition in Ancient India', Information Studies, 16(4), pp. 215-228.

Sagala, S. (2015) 'MANAJEMEN DAN KEPEMIMPINAN PENDIDIKAN PONDOK PESANTREN', JURNAL TARBIYAH, 22(2), pp. 205-225.

Satori, Djam'an, Aan Komariyah. (2010). Metodologi Penelitian Kualitatif. Bandung: Alfabeta.

Sila, I. M. (2016). Revitalisasi Manajemen Pasraman Dalam Menumbuhkan Sikap Revolusi Mental Secara Berkelanjutan Pada Pasraman Di Desa Puhu Kacamatan Payangan. Widya Accarya, 6(2).

Subagia, I. N. (2017). Keberadaan Pasraman Sebagai Penguatan Budaya Lokal Dikaitkan Dengan Peraturan Pemerintah Nomor 55 Tahun 2007. VIDYA SAMHITA: Jurnal Penelitian Agama, 2(2).

Suhardana, K.M. (2007). Tri Kaya Parisuda. Surabaya,Paramita.

Trammell, M. G. (1999) A study of the effects of spiritual commitment and intervention on communication apprehension, ProQuest Dissertations and Theses. Available at: http:/ / search.proquest.com/docview/304544932?accountid=14553\%5Cnhttp:/ / 
openurl.library.uiuc.edu/sfxlcl3?url_ver=Z39.882004\&rft_val_fmt=info:ofi/fmt:k ev:mtx:dissertation\&genre=dissertations $+\&+$ theses\&sid=ProQ:ProQuest+Dissert ations $+\&+$ Theses + Full + Text\&atitle $=$.

Undang-Undang Republik Indonesia No.20 Tahun 2003 tentang Sistem Pendidikan Nasional.

Widnya, I K. (2017). Bianglala Peradaban Hindu. Denpasar: ESBE Buku.

Yuli, N. G., Haningsih, S. and Adikrishna, R. (2011) 'Boarding School: A Preliminary Research in', International Jornal of Engineering \& Technology, 11(4), pp. 156-163. 